Article

\title{
In Situ High Pressure Structural Investigation of Sm-Doped Ceria
}

\author{
Cristina Artini ${ }^{1,2, *}$, Sara Massardo ${ }^{1}$, Maria Maddalena Carnasciali ${ }^{1,3}$, Boby Joseph ${ }^{4}([)$ and \\ Marcella Pani ${ }^{1,5}$ \\ 1 Department of Chemistry and Industrial Chemistry, University of Genova, 16146 Genova, Italy; \\ s.massardo93@gmail.com (S.M.); marilena@chimica.unige.it (M.M.C.); marcella@chimica.unige.it (M.P.) \\ 2 Institute of Condensed Matter Chemistry and Technologies for Energy, National Research Council, \\ CNR-ICMATE, 16149 Genova, Italy \\ 3 INSTM, Genova Research Unit, Via Dodecaneso 31, 16146 Genova, Italy \\ 4 GdR IISc-ICTP, Elettra-Sincrotrone Trieste S.C.p.A., ss 14, km 163.5, 34149 Trieste, Basovizza, Italy; \\ boby.joseph@elettra.eu \\ 5 CNR-SPIN, 16152 Genova, Italy \\ * Correspondence: artini@chimica.unige.it; Tel.: +39-010-353-6082
}

Received: 22 January 2020; Accepted: 23 March 2020; Published: 27 March 2020

\begin{abstract}
As a result of the lattice mismatch between the oxide itself and the substrate, the highpressure structural properties of trivalent rare earth (RE)-doped ceria systems help to mimic the compressive/tensile strain in oxide thin films. The high-pressure structural features of Sm-doped ceria were studied by X-ray diffraction experiments performed on $\mathrm{Ce}_{1-x} \mathrm{Sm}_{x} \mathrm{O}_{2-x / 2}(x=0.2,0.3,0.4$, $0.5,0.6)$ up to $7 \mathrm{GPa}$, and the cell volumes were fitted by the third order Vinet equation of state (EoS) at the different pressures obtained from Rietveld refinements. A linear decrease of the $\ln B_{0}$ vs. $\ln \left(2 V_{a t}\right)$ trend occurred as expected, but the regression line was much steeper than predicted for oxides, most probably due to the effect of oxygen vacancies arising from charge compensation, which limits the increase of the mean atomic volume $\left(V_{a t}\right)$ vs. the Sm content. The presence of $\mathrm{RE}_{2} \mathrm{O}_{3}$-based cubic microdomains within the sample stiffens the whole structure, making it less compressible with increases in applied pressure. Results are discussed in comparison with ones previously obtained from Lu-doped ceria.
\end{abstract}

Keywords: solid oxides fuel cells; Sm-doped ceria; high pressure X-ray powder diffraction; diamond anvil cell; equation of state; Rietveld refinement

\section{Introduction}

Trivalent rare earth (RE)-doped ceria systems form a group of widely studied mixed oxides with technologically interesting values of ionic conductivity in the intermediate temperature range (673-973 K), which make them useful as solid electrolytes in solid oxide fuel cells (SOFCs). $\mathrm{Ce}_{0.9} \mathrm{RE}_{0.1} \mathrm{O}_{1.95}$ oxides $(\mathrm{RE}=\mathrm{Gd}, \mathrm{Sm}, \mathrm{Nd})$ present values of ionic grain conductivity ranging between $5 \times 10^{-2}$ and $7 \times 10^{-2}$ $\mathrm{S} \mathrm{cm}^{-1}$ at $773 \mathrm{~K}$, with a remarkable increase occurring with increases of the RE ionic radius [1]. However, even a slight variation in RE content causes a non-negligible change in ionic conductivity; $\mathrm{Ce}_{0.8} \mathrm{Gd}_{0.2} \mathrm{O}_{1.90}$, for example, is characterized by a total ionic conductivity of $1 \times 10^{-3} \mathrm{~S} \mathrm{~cm}^{-1}$ at $773 \mathrm{~K}$ [2]. Ionic conductivity is in fact affected by many factors such as RE identity, composition, structure and microstructure of the oxide [3-7], and not least by the occurrence of the sample in the bulk or thin film form. With particular reference to this latter issue, thin films are essential when designing SOFC-based portable devices because of the need for fabricating fuel cells on chips $[8,9]$. Nevertheless, thermodynamic, structural and transport properties of the deposited electrolyte are 
not necessarily the same as in the bulk material; deposited Gd-doped ceria electrolytes, for instance, present ohmic losses up to 100 times lower than the corresponding oxides in bulk form [8], which is one of the main advantages to using doped ceria thin films. These issues make the investigation of such properties, and comparison with the ones of the bulk materials, of primary importance. In particular, it is known that the thinning of layer thickness often induces a significant ionic conductivity increase in doped ceria due to the oxide/substrate lattice mismatch [10,11], while at the same time causing a significant decrease in the same property due to a larger amount of defects [8]. The aim of this study is to separate these two competitive effects, as the high-pressure behavior of bulk samples can help to simulate the strain at the interface. The application of $5 \mathrm{GPa}$, for instance, roughly corresponds to a $1 \%$ compressive strain, which is not far from the one existing in a 250-nm-thick Gd-doped ceria film deposited on a $\mathrm{MgO} / \mathrm{SrTiO}_{3}$ layer [11]. Only a few papers in the literature have discussed the high-pressure structural properties of doped ceria [12,13]. Lattice mismatch is one of the main causes of microstrain at the interface $[11,14]$, but for the sake of completeness it should also be noted that microstrain derives from thermal expansion coefficient mismatch or from properties resulting from processing issues (such as grain size) [8].

Together with Gd- and Nd-doped ceria, Sm-doped ceria is one of the most effective systems of ionic conductivity [1]. Ionic conductivity is strictly related to structural and microstructural issues, and this is the reason why so many papers in recent years have been devoted to the crystallographic properties of this material, even in the light of the non-negligible effects of extrinsic factors (e.g., thermal treatments) on the stability of the various oxide phases $[15,16]$. A particular attention has been paid to defect aggregations [3,17-21], since ionic conductivity in doped ceria occurs through the hopping of oxygen ions towards the vacancies $\left(V_{\ddot{O}}\right)$ created for charge compensation when $\mathrm{Ce}^{4+}$ is partially substituted by $\mathrm{RE}^{3+}$. The mechanism works until the fluorite-type cubic structure of $\mathrm{CeO}_{2}$ (hereafter named $F$; space group: $F m \overline{3} m$; Ce coordination number: 8 ) is retained (i.e., until the solid solution of $\mathrm{RE}^{3+}$ within the $\mathrm{CeO}_{2}$ matrix is stable). Actually, maximum ionic conductivity for the solid F solution falls well within the stability range; for example, the compositional limit of $\mathrm{F}$ in $\mathrm{Ce}_{1-x} \mathrm{Gd}_{x} \mathrm{O}_{2-x / 2}$ is located at $x \sim 0.2$ [22], with its maximum conductivity at $x=0.10-0.15[4,23]$. This evidence is due to the creation of defect aggregates $R E_{C e}^{\prime}: V_{\ddot{O}}$ having the cubic structure of sesquioxides $\mathrm{RE}_{2} \mathrm{O}_{3}$ (hereafter named $C$; space group: Ia $\overline{3}$; RE coordination number: 6 ), which hinder the movement of oxygen ions. Due to their nanometric size, $C$ aggregates are invisible to $X$-ray diffraction until the $\mathrm{RE}^{3+}$ amount reaches a threshold content that is defined by the RE's identity. On the contrary, $C$ aggregates can also be revealed by Raman spectroscopy, due to the superior sensitivity of the latter technique toward oxygen displacement. Therefore, the position of the upper compositional limit of $\mathrm{F}$ as obtained from $\mathrm{X}$-ray diffraction does not necessarily coincide with the limit deriving from Raman spectroscopy (i.e., $x \sim 0.3$ and ranging between $x=0.2$ and 0.3 in $\mathrm{Ce}_{1-x} \mathrm{Sm}_{x} \mathrm{O}_{2-x / 2}$ for the former and latter techniques, respectively) [24]. For Sm-doped ceria beyond the F limit, this system presents an intermediate structure between $F$ and $C$, as $F$ and $C$ are linked to each other through a structure/superstructure relation and-due to the close resemblance of the $\mathrm{Ce}^{4+}$ and $\mathrm{Sm}^{3+}$ ionic sizes $\left(\mathrm{Ce}^{4+}, \mathrm{CN}: 8, r=0.97 \AA ; \mathrm{Sm}^{3+}, \mathrm{CN}: 6, r=0.958 \AA\right.$ [25])—peaks common to the two phases coincide, regardless of the sensitivity of the diffractometer employed [22]. This atomic arrangement, which can be interpreted as a solid solution with the $S m^{\prime} \mathrm{Ce}_{e}: V_{\ddot{O}}$ C-based domains acting as guests [24] was named $\mathrm{H}$ due to its hybrid character between $\mathrm{F}$ and $\mathrm{C}$, and has even been described for other systems, such as Y- [26] and Gd-doped ceria [27]. Moreover, as a direct consequence of the structure/superstructure relation, the $\mathrm{H}$ cell parameter is roughly double that of $F$.

In the framework of a high-pressure structural study of doped ceria, it is very interesting to compare the properties of a system presenting the $\mathrm{H}$ phase (such as $\mathrm{Sm}$-doped ceria) to that of a system that-due to ionic dimensional issues—behaves differently. In this respect, Lu-doped ceria $\left(\mathrm{Ce}_{1-x} \mathrm{Lu}_{x} \mathrm{O}_{2-x / 2}\right)$ act as an ideal model: While the $\mathrm{CeO}_{2}$-based solid solution with $\mathrm{Lu}^{3+}$ as a guest forms up to $x \sim 0.4$ [28], the large ionic size difference $\left(\mathrm{Ce}^{4+}, \mathrm{CN}: 8, r=0.97 \AA\right.$; $\mathrm{Lu}^{3+}, \mathrm{CN}: 6, r=0.861$ $\AA$ [25]) prevents the formation of the $H$ phase and promotes the stability of a $(F+C)$ two-phase field. 
In this work the high-pressure structural properties of Sm-doped ceria were studied by analyzing X-ray diffraction patterns collected up to 7 GPa at the XPRESS diffraction beamline of the Elettra Synchrotron radiation facility [29]. The refined cell volumes were fitted to the Vinet equation of state (EoS) [30], and the obtained bulk moduli at zero pressure $\left(B_{0}\right)$ were discussed in comparison to the ones obtained for Lu-doped ceria in a previous study [13]. A substantial insensitivity of $B_{0}$ to structural changes was revealed for both systems, while the compressibility of compositions containing $\mathrm{C}$ domains remarkably decreased starting from $\sim 3 \mathrm{GPa}$. A significant effect of vacancies was also found for the trend of $\ln B_{0}$ vs. $\ln \left(2 V_{a t}\right)$ (with $2 V_{a t}$ being the volume per atom pair).

\section{Materials and Methods}

\subsection{Synthesis}

Five compositions belonging to the $\mathrm{Ce}_{1-x} \mathrm{Sm}_{x} \mathrm{O}_{2-x / 2}$ system with nominal $x=0.2,0.3,0.4,0.5$ and 0.6 were synthesized by oxalate coprecipitation [31,32]. Stoichiometric amounts of Ce (Johnson Matthey ALPHA 99.99\% wt.) and $\mathrm{Sm}_{2} \mathrm{O}_{3}$ were separately dissolved in $\mathrm{HCl}(13 \%$ vol.), then the two solutions were mixed together. Afterwards, the precipitation of the mixed Ce/Sm oxalate was accomplished by adding a solution of oxalic acid in large excess. Oxalates were filtered, washed and dried for $12 \mathrm{~h}$ then thermally treated at $1373 \mathrm{~K}$ in air for four days to obtain mixed oxides with a high degree of crystallinity.

\subsection{Scanning Electron Microscopy-Energy-Dispersive System (SEM-EDS)}

Scanning electron microscopy-energy-dispersive system (SEM-EDS, Oxford Instruments, model 7353 with Oxford-INCA software v. 4.07) was employed to check the overall rare earth contents of all the samples. Pellets of powders pressed and sintered at $1773 \mathrm{~K}$ were coated by a graphite layer and analyzed at a working distance of $15 \mathrm{~mm}$, with an acceleration voltage of $20 \mathrm{kV}$. EDS analyses were carried out on at least six points for each sample.

\subsection{High-Pressure Synchrotron X-ray Powder Diffraction (HP-XRPD)}

Ambient and high-pressure X-ray powder diffraction acquisitions were done at the XPRESS diffraction beamline of the Elettra Synchrotron radiation facility located in Trieste (Italy) [29]. Data collection was performed by a monochromatic circular beam with a wavelength of $0.4957 \AA$ and a diameter around $50 \mu \mathrm{m}$; pressure was applied from 0 to $\sim 7 \mathrm{GPa}$ using a gear-driven Boehler-Almax plate diamond anvil cell (plate DAC) with a large X-ray aperture containing diamonds with a culet size of $500 \mu \mathrm{m}$. In order to arrange the sample chamber, $200-\mu \mathrm{m}$-thick rhenium gaskets were pre-indented using the plate DAC, thus obtaining a thickness of about $110 \mu \mathrm{m}$; a through-hole with a diameter of $200 \mu \mathrm{m}$ was subsequently drilled by spark erosion at the center of the pre-indented region. Fine powders of the sample were placed inside the sample chamber to obtain diffraction data with minimal preferred orientation effects. Pressure calibration was done either by $\mathrm{Cu}$, making use of the $\mathrm{Cu}$ (111) diffraction peak (for samples Sm20 and Sm30), or by ruby, measuring the displacement in the position of its fluorescence lines (for samples Sm40, Sm50 and Sm60). The sample chamber was filled with silicon oil as pressure transmitting medium (PTM), and the diamonds of the anvil cell were subsequently brought into contact with the gasket. The PTM chosen provided good hydrostatic pressure conditions up to the maximum pressure applied in the present study. A schematic representation of the experimental set-up is shown in Figure 1.

The experimental station was equipped with a MAR345 image plate detector, and images of the powder diffraction rings were converted into $2 \theta$-intensity plots by means of the fit $2 \mathrm{D}$ software. The angular range spanned between $4^{\circ}$ and $30^{\circ}$. Samples were named Sm20_7.54, Sm30_5.23 and so on, according to the nominal Sm atomic percent with respect to the total $(\mathrm{Ce}+\mathrm{Sm})$ content and applied pressure. 


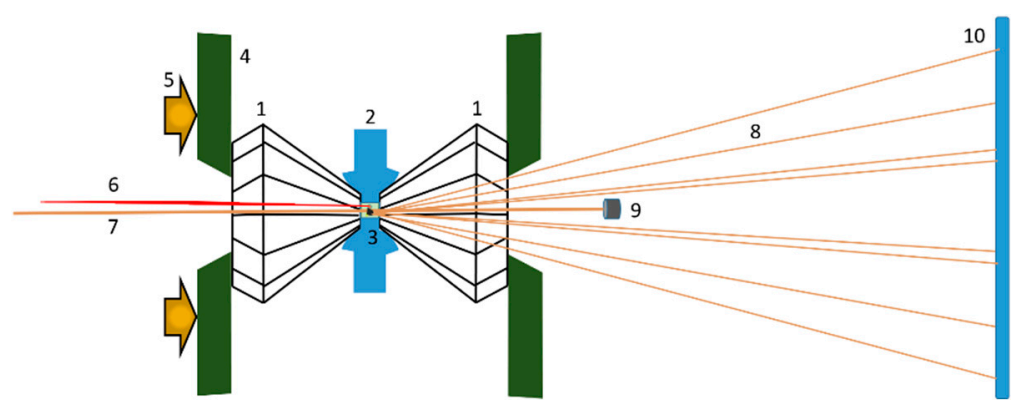

Figure 1. Scheme of the experimental set-up at the XPRESS beamline. (1) Pair of identical diamonds; (2) metal foil with a hole at the center (sample chamber); (3) sample chamber (sample, ruby, pressure transmitting medium (PTM)); (4) backing plates holding diamonds; (5) force pushing diamonds; (6) laser for ruby fluorescence excitation; (7) incident monochromatic X-ray microbeam; (8) diffracted X-rays; (9) beam stop blocking the direct beam; (10) image plate detector recording the position and intensity of the diffracted X-rays.

The FullProf suite [33] was used to refine structural models using the Rietveld method; the evolution of the lattice volume as a function of pressure was modeled through the third order Vinet EoS [30] by means of the EosFit7-Gui software [34]. High-pressure data are discussed in comparison to data collected using the same samples at ambient pressure at the MCX beamline, as described in [24] as well as to the samples of Lu-doped ceria collected at high pressure at the XRD1 beamline [12].

\section{Results}

\subsection{Compositional Characterization}

The experimental $x$ of all the samples, as revealed by EDS, was found very close to the stoichiometric value, and results are reported in Table 1 . Therefore, the occupancy factors of crystallographic sites hosting lanthanide ions were fixed at the nominal value and not refined during Rietveld cycles. No extra phases were detected, and backscattered images taken on the polished surfaces of all samples did not reveal the presence of any color inhomogeneity, as shown in Figure 2 with reference to sample $\operatorname{Sm} 40$.

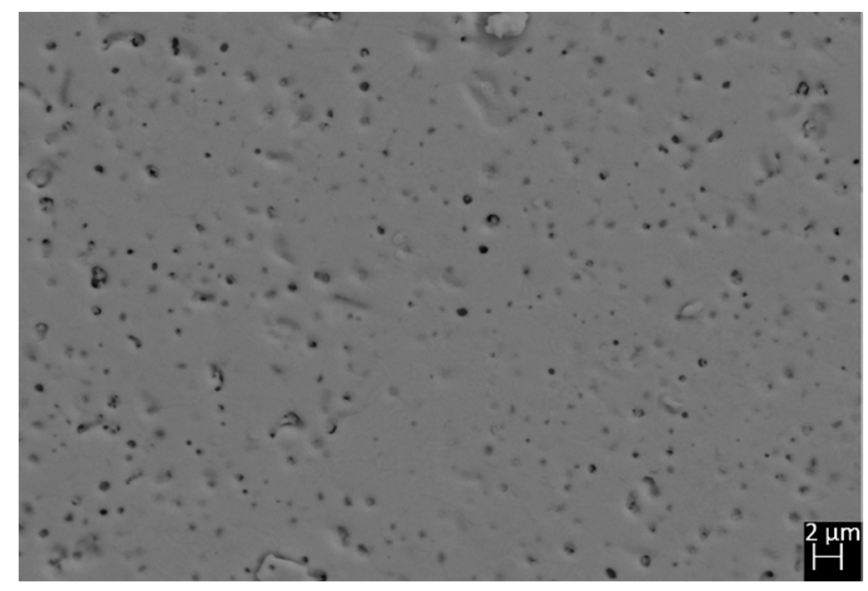

Figure 2. Microphotograph taken by backscattered electrons on the polished surface of sample Sm40. 
Table 1. Mean experimental $x$ values as revealed by EDS analyses.

\begin{tabular}{cc}
\hline Sample & Experimental $x$ in $\mathrm{Ce}_{\mathbf{1 - x}} \mathbf{S m}_{x} \mathbf{O}_{2-x / \mathbf{2}}$ \\
\hline Sm20 & $0.17(1)$ \\
Sm30 & $0.30(1)$ \\
Sm40 & $0.38(1)$ \\
Sm50 & $0.48(1)$ \\
Sm60 & $0.60(1)$ \\
\hline
\end{tabular}

\subsection{Structural Characterization}

Peaks belonging to either the $\mathrm{F}$ or $\mathrm{H}$ phases were imposed to refine two different structural models according to their composition; namely, the F model for the Sm20 and Sm30 samples, and the H model for the Sm40, Sm50 and Sm60 samples. The F structure consisted of a cubic cell belonging to the $F m \overline{3} m$ space group comprising four formula units per cell [35]; the two atomic positions were occupied by $\mathrm{Ce} / \mathrm{Sm}(0,0,0)$ and $\mathrm{O}(1 / 4,1 / 4,1 / 4)$. The $H$ phase was a solid solution of $\mathrm{C}$ domains within the $\mathrm{CeO}_{2}$ matrix. The $\mathrm{C}$ structure consisted of a cubic cell belonging to the $I a \overline{3}$ space group and comprising 32 formula units per cell. The atomic rearrangement with respect to $F$ induced the position occupied by rare earths to split into two distinct crystallographic sites. Both the $F$ and the $C$ structural models are reported in the Supplementary Materials.

It is questionable whether the pyrochlore $(\mathrm{P})$ structure even occurred in the studied samples at this stage. Pyrochlore is the name of the $(\mathrm{Na}, \mathrm{Ca})_{2} \mathrm{Nb}_{2} \mathrm{O}_{6}(\mathrm{OH}, \mathrm{F})$ mineral, which crystallizes in the $F d \overline{3} m$ space group. It differs from the $\mathrm{C}$ structure just in regards to the position of oxygen vacancies, which are located in the next-nearest-neighbor sites with respect to $\mathrm{RE}^{3+}$, while in the $\mathrm{C}$ structure they are placed in nearest-neighbor positions. In this sense, the P-type structure represents an alternative arrangement of defects in doped ceria. Due to the different extinction rules of the face-centered lattice of the $\mathrm{P}$ structure with respect to the body-centered one of the $\mathrm{C}$, the reflections of the crystallographic planes (331) and (333) + (511) should be visible in the diffraction pattern in case of occurrence of the $P$ phase, albeit with low intensity; since this condition is not fulfilled, we can exclude the presence of $\mathrm{P}$ in our samples. This conclusion is also supported by the literature, as is discussed hereafter. In principle, the presence of a $\mathrm{Ce}_{2} \mathrm{RE}_{2} \mathrm{O}_{7}$ P-type phase in rare earth (RE)-doped ceria cannot be ruled out a priori; D.E.P. Vanpoucke et al. [36], for example, claimed there is a higher stability of $P$ with respect to the $\mathrm{F}$ phase for $\mathrm{Ce}_{2} \mathrm{La}_{2} \mathrm{O}_{7}$ based on density functional theory (DFT) calculations. Relying on the comprehensive theoretical study by L. Minervini and R.W. Grimes [37], $\mathrm{Ce}_{2} \mathrm{La}_{2} \mathrm{O}_{7}$ has in fact been located at the $\mathrm{P} / \mathrm{F}$ boundary, and its occurrence in the $\mathrm{P}$ phase cannot be excluded. Nevertheless, the stability range of $\mathrm{A}_{2} \mathrm{~B}_{2} \mathrm{O} 7$ compounds (being $\mathrm{A}$ and $\mathrm{B}$ transition metals or lanthanide ions) is reported to depend on the $\mathrm{A} / \mathrm{B}$ cationic ratio, and all the ceria-based systems doped with lanthanide ions smaller than $\mathrm{La}$ (i.e., from $\mathrm{Nd}$ to $\mathrm{Lu}$ ) have been determined to be more stable in the $F$ phase [37]. Even the exhaustive paper by W. Chen and A. Navrotsky [38], which makes use of the atomistic results by L. Minervini et al. [39], states that the formation enthalpies of $\mathrm{Ce}_{2} \mathrm{RE}_{2} \mathrm{O}_{7}$ become thermodynamically unfavored when decreasing the $\mathrm{RE}^{3+}$ size, being $-102 \mathrm{~kJ} / \mathrm{mol}$ for $\mathrm{Ce}_{2} \mathrm{La}_{2} \mathrm{O}_{7},-3.85 \mathrm{~kJ} / \mathrm{mol}$ for $\mathrm{Ce}_{2} \mathrm{Gd}_{2} \mathrm{O}_{7}$ and $175 \mathrm{~kJ} / \mathrm{mol}$ for $\mathrm{Ce}_{2} \mathrm{Y}_{2} \mathrm{O}_{7}$. For the sake of completeness, simulations performed by B. Wang et al. [40] showed that stable P defect clusters in Gd-doped ceria are expected to occur only when they form within ceria matrix domains in the sub-nanoscale range (i.e., at very low dopant amounts). On the basis of this experimental evidence, as well the other described considerations, we can thus exclude the occurrence of $\mathrm{P}$ phase in the current studied samples.

The location of the $F / H$ boundary being close to $x \sim 0.3$ in $\mathrm{Ce}_{1-x} \mathrm{Sm}_{x} \mathrm{O}_{2-x / 2}$ agrees with previous studies performed using X-ray diffraction on the same system in room [24] and high-temperature [41] conditions. Very interestingly, as briefly mentioned in Section 1, these results differ slightly from the outcome of Raman spectroscopy, which has revealed the presence of a tiny amount of C-based domains even in Sm30 through the occurrence of a weak signal at $\sim 370 \mathrm{~cm}^{-1}$, which was caused by the $\left(A_{g}+F_{g}\right)$ $\mathrm{Sm}-\mathrm{O}$ symmetrical stretching mode with $\mathrm{Sm}$ in a six-fold coordination [42]. The described discrepancy 
between data of X-ray diffraction and Raman spectroscopy is not surprising, as it was already observed for other similar systems, such as Tm-doped ceria [43]. This is due to the very high sensitivity of the latter technique toward oxygen displacement, which gives it the ability to clearly discriminate between the $F$ and $C$ structures. On the contrary, $X$-ray diffraction patterns of the two phases are essentially superimposable, with the only difference being the presence of the weak superstructure peaks in C. In Figure 3, the Rietveld refinement plot of sample Sm50_6.94 is reported as a representative example; the refined parameters and Rietveld agreement factors are collected in Table 2.

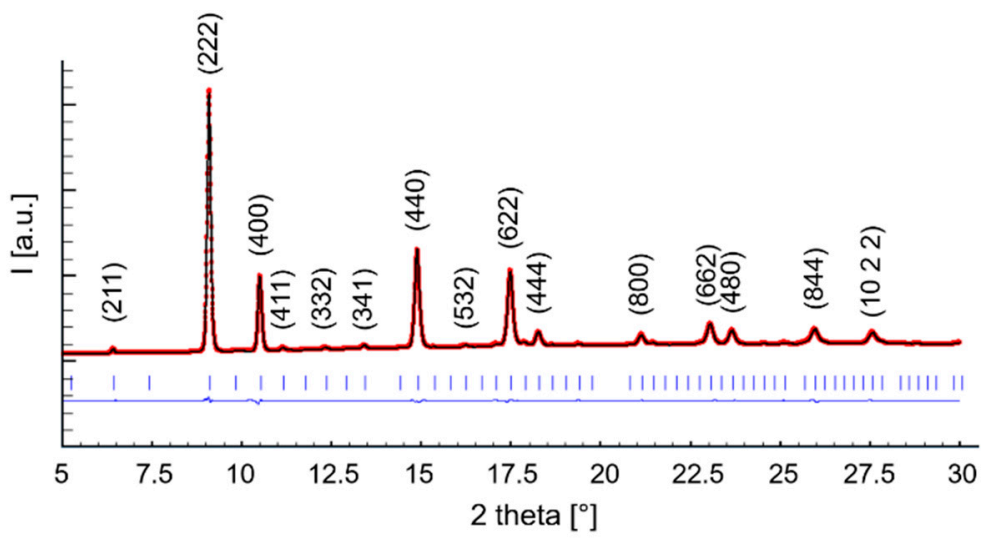

Figure 3. Rietveld refinement plot of sample Sm50_6.94. The dotted (red) and the continuous (black) lines are the experimental and the calculated diffractograms, respectively; the lower line is the difference curve; vertical bars indicate the calculated positions of Bragg peaks. Miller indexes related to the $\mathrm{H}$ structure (space group $I a \overline{3}$ ) are reported too.

For each diffraction pattern the peak profile was refined by the pseudo-Voigt function, while the background was optimized by linear interpolation of a set of $\sim 70$ experimental points. For samples $\mathrm{Sm} 20$ and Sm30, the angular regions where peaks of $\mathrm{Cu}$ appear were excluded from refinements. In the last cycle, structural parameters (cell parameters; and for the $H$ phase: the $\mathrm{Ce} / \mathrm{Sm} 1 x$ coordinate, the $\mathrm{O} 1$ $x, y$ and $z$ coordinates and both the occupancy factor and $x$ coordinate of $\mathrm{O} 2)$, atomic displacement parameters, the scale factor, five peak parameters and the background points were refined. For each composition, high-pressure data were optimized using atomic positions refined at ambient pressure as starting parameters.

Table 2. Applied pressure, refined cell parameter and Rietveld agreement factors for each studied sample.

\begin{tabular}{ccccc}
\hline Sample & $\boldsymbol{P}(\mathrm{GPa})$ & $\boldsymbol{A}$ Cell Parameter $(\AA)$ & $\boldsymbol{R}_{\boldsymbol{B}}{ }^{\mathbf{a}}$ & $\boldsymbol{\chi}^{\mathbf{2}}$ \\
\hline \multirow{5}{*}{ Sm20 } & 0 & $5.43531(5)$ & 0.62 & 0.199 \\
& 2.75 & $5.41524(7)$ & 0.48 & 0.384 \\
& 3.45 & $5.40982(8)$ & 0.81 & 0.613 \\
& 4.20 & $5.40673(4)$ & 0.50 & 0.829 \\
& 4.88 & $5.3966(1)$ & 0.54 & 0.462 \\
& 7.54 & $5.3773(2)$ & 0.64 & 0.569 \\
\hline \multirow{5}{*}{ Sm30 } & 0 & $5.44092(5)$ & 1.27 & 0.82 \\
& 1.15 & $5.43080(5)$ & 0.90 & 0.66 \\
& 1.85 & $5.42734(6)$ & 1.08 & 0.44 \\
& 1.95 & $5.42615(7)$ & 0.57 & 0.45 \\
& 2.18 & $5.42500(9)$ & 0.89 & 0.59 \\
& 2.63 & $5.4233(1)$ & 1.12 & 0.84 \\
& 2.99 & $5.4212(1)$ & 0.98 & 0.66 \\
& 4.18 & $5.4142(2)$ & 0.93 & 0.60 \\
& 5.23 & $5.4081(2)$ & 0.78 & 1.05 \\
\hline
\end{tabular}


Table 2. Cont.

\begin{tabular}{|c|c|c|c|c|}
\hline Sample & $P(\mathrm{GPa})$ & A Cell Parameter (Å) & $R_{B}{ }^{a}$ & $\chi^{2 \mathrm{~b}}$ \\
\hline \multirow{7}{*}{$\operatorname{Sm} 40$} & 0 & $10.89875(6)$ & 3.67 & 2.47 \\
\hline & 2.42 & $10.8646(1)$ & 1.23 & 0.972 \\
\hline & 3.00 & $10.8629(2)$ & 0.89 & 0.620 \\
\hline & 3.17 & $10.8551(2)$ & 0.76 & 0.468 \\
\hline & 3.73 & $10.8557(3)$ & 0.77 & 0.549 \\
\hline & 4.11 & $10.8548(4)$ & 0.61 & 0.553 \\
\hline & 4.67 & $10.8484(4)$ & 0.60 & 0.44 \\
\hline \multirow{10}{*}{ Sm50 } & 0 & $10.91507(5)$ & 2.52 & 0.723 \\
\hline & 0.20 & 10.91561(5) & 1.85 & 0.451 \\
\hline & 1.11 & $10.89095(5)$ & 1.95 & 0.551 \\
\hline & 1.30 & $10.89046(5)$ & 2.29 & 0.652 \\
\hline & 1.86 & $10.87945(6)$ & 1.72 & 0.466 \\
\hline & 2.60 & $10.86725(5)$ & 1.62 & 0.540 \\
\hline & 3.92 & 10.84993(8) & 1.17 & 0.486 \\
\hline & 5.05 & $10.8349(1)$ & 0.95 & 0.381 \\
\hline & 6.94 & $10.8159(1)$ & 0.75 & 0.324 \\
\hline & 7.32 & $10.8144(1)$ & 0.68 & 0.331 \\
\hline \multirow{8}{*}{ Sm60 } & 0.74 & $10.90674(4)$ & 1.51 & 0.849 \\
\hline & 1.58 & $10.89078(5)$ & 1.52 & 0.814 \\
\hline & 2.98 & $10.86970(7)$ & 1.43 & 0.465 \\
\hline & 4.11 & $10.85667(9)$ & 1.14 & 0.359 \\
\hline & 4.86 & $10.8490(1)$ & 0.92 & 0.252 \\
\hline & 5.43 & $10.8460(2)$ & 0.71 & 0.22 \\
\hline & 6.00 & $10.8389(2)$ & 0.53 & 0.20 \\
\hline & 6.56 & $10.8355(3)$ & 0.48 & 0.19 \\
\hline
\end{tabular}

Diffraction patterns collected from sample Sm50 at all the pressure values are shown in Figure 4 as representative examples of the behavior of all the compositions. No additional peaks can be observed by increasing the applied pressure with respect to the ones typical of the $\mathrm{F}$ or $\mathrm{H}$ structures; on the contrary, as evident from the inset, a shift toward higher diffraction angles occurred, indicating a lattice size reduction due to compression.

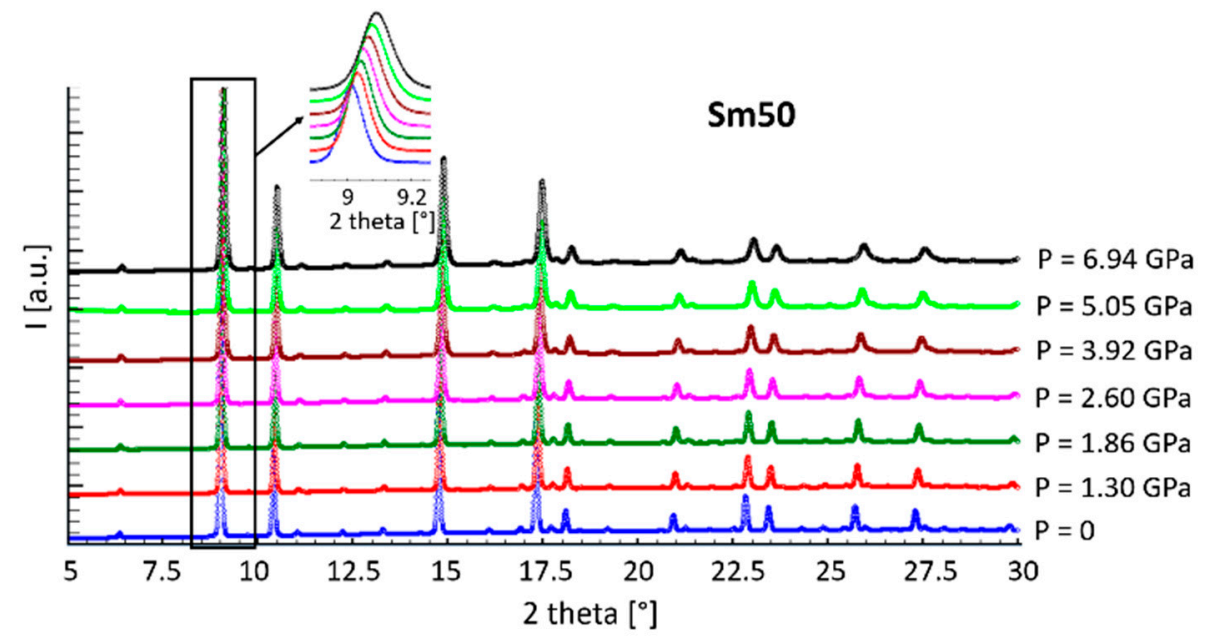

Figure 4. Diffraction patterns of sample Sm50 at all pressure values.

In Figure 5, the refined values of the lattice volume of each sample are reported as a function of the applied pressure. Within the considered pressure range, the cell volume decreased with pressure, and 
it can be observed that the trend was roughly linear for sample Sm20, while all the other compositions had a progressively more marked softening of the decrease starting from $\sim 3 \mathrm{GPa}$, which is in agreement with the compressibility reduction that occurred with increases in applied pressure. No significant differences were observed with changing pressure among the refined values of the $\operatorname{Sm} 1 x$ coordinate.

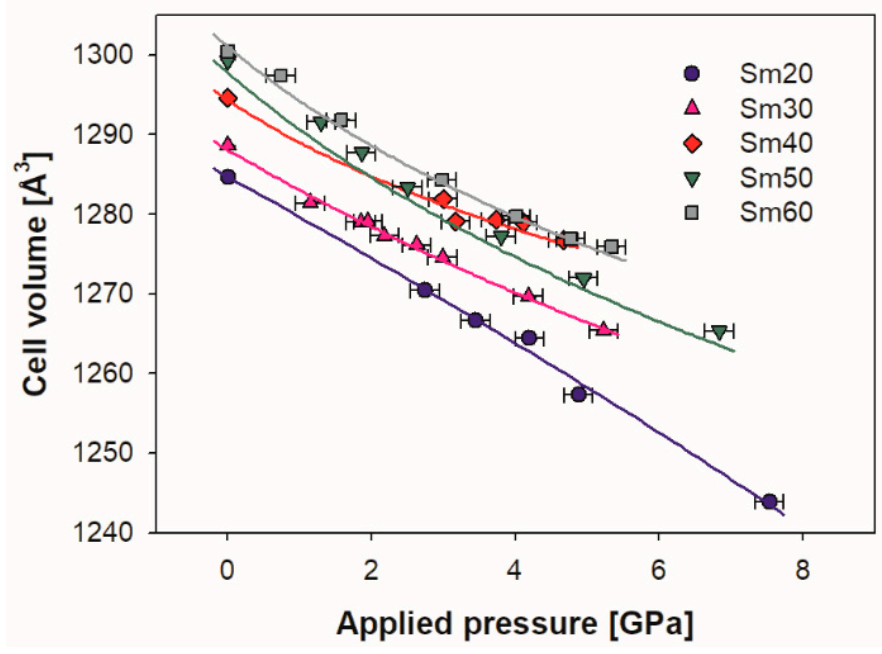

Figure 5. Evolution with pressure of the Sm-doped ceria cell volume for all the samples; experimental data are fitted by the third order Vinet EoS (continuous lines). Cell volumes of samples Sm20 and Sm30 are multiplied by 8 in order to make them comparable with those of Sm40, Sm50 and Sm60. Vertical error bars are hidden by data markers.

The bulk modulus that occurred at zero pressure $\left(B_{0}\right)$ accounts for the resistance of a material to compression, and is defined as

$$
B_{0}=-V_{0}\left(\frac{\partial P}{\partial V}\right)_{P=0}
$$

where $V_{0}$ is the cell volume at $P=0 . B_{0}$ can be estimated by fitting the refined lattice volumes (or cell parameters) obtained at different applied pressures to the proper equation of state. Several different EoSs were proposed in equations by Murnaghan [44], Birch-Murnaghan [45], Vinet [30] and Poirier-Tarantola [46], all of which were able to correctly predict the bulk modulus at ambient conditions [47]. All the aforementioned EoSs describe and model the pressure-volume correlation of a solid through the bulk modulus and its pressure derivatives. The Vinet EoS, for instance, is an exponential function with the following form:

$$
P(V)=\frac{3 B_{0}}{X^{2}}(1-X) \exp \left[\eta_{0}(1-X)\right]
$$

with

$$
X=\left(\frac{V}{V_{0}}\right)^{1 / 3}
$$

and

$$
\eta_{0}=\frac{3}{2}\left[B \prime_{0}-1\right]
$$

In this work experimental data were fitted by the Vinet EoS, and fits of refined cell volumes vs. pressure are reported in Figure 5. The optimized $B_{0}$ as a function of Sm content appears in Figure 6 together with two $B_{0}$ values of $\mathrm{CeO}_{2}$ chosen from the literature, which were obtained using the Hartree-Fock method [48] and through X-ray diffraction [49]. It is worth noting that $B_{0}$ values of $\mathrm{CeO}_{2}$ available in the literature spanned a wide range, according to the employed technique [50]. A roughly linear decrease of $B_{0}$ with increasing Sm content can be observed in Figure 6. 


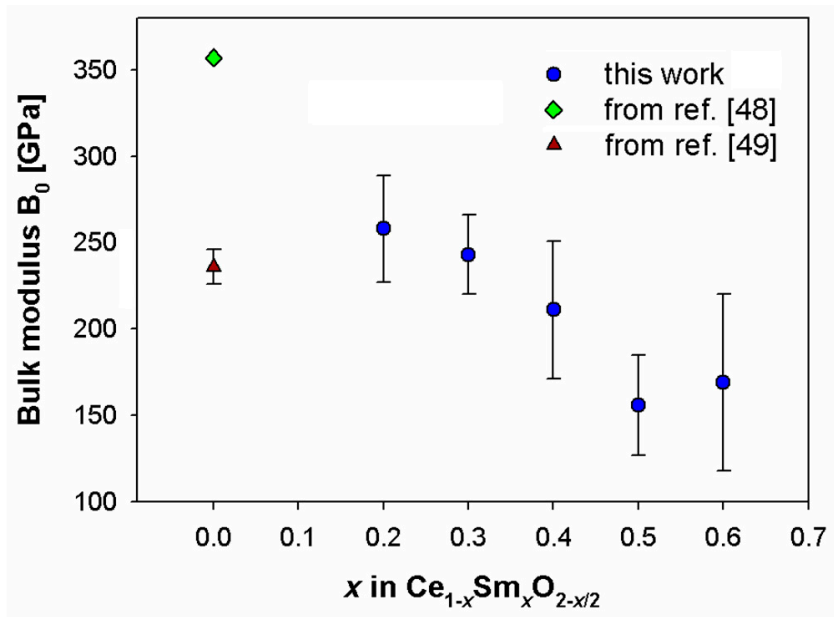

Figure 6. Zero-pressure bulk modulus $\left(B_{0}\right)$ as a function of the $\mathrm{Sm}$ content alongside literature data for $\mathrm{CeO}_{2}[48,49]$.

\section{Discussion}

The dependence of $\mathrm{B}_{0}$ on Sm content can be analyzed and discussed in the light of the fundamental paper by Anderson and Nafe [51], which provides the theoretical background behind the behavior of $B_{0}$ in oxides. According to this work, a correlation exists between $B_{0}$ and the mean volume per ion pair (namely $2 V_{a t}$, calculated as the volume of a cell divided by the halved number of atoms therein contained). This correlation assumes different forms for ionic crystals and oxides. In particular, the expression

$$
\ln B_{0}=-\ln \left(2 V_{a t}\right)+\ln \left(Z_{1} \times Z_{2}\right)+\text { constant }
$$

with $Z_{1}$ and $Z_{2}$ as the cationic and anionic charge, respectively, applies to ionic crystals, while

$$
\ln B_{0}=-m \ln \left(2 V_{a t}\right)+\text { constant }
$$

with $m$ ranging between 3 and 4 , is valid for oxides. A decreasing linear trend is observed in both cases, which accounts for the progressively increasing compressibility of a solid with an increasing mean atomic volume. Relying on Equations (5) and (6), it is thus clear that oxides are characterized by a much stronger dependence of $B_{0}$ on atomic volume.

In Figure 7 , the diagram of $\ln B_{0}$ as a function of $\ln \left(2 V_{a t}\right)$ for Sm-doped ceria is shown, with $B_{0}$ values obtained from the EoS fits, and $2 V_{a t}$ derived from the refined cell volumes. Firstly, it can be observed that the trend of data is decreasing and roughly linear.

It should be remembered at this point that, similar to all RE-doped ceria systems-where the total number of atoms changes with an increasing amount of RE-a linear correlation exists between the atomic mean volume and the doping ion amount, even in Sm-doped ceria, according to Zen's law [52]. This issue, widely discussed in [3,24], points to the existence of a solid solution along the whole compositional range, where the guests are $\mathrm{Sm}^{3+}$ ions within the $\mathrm{F}$ region and $\mathrm{Sm}_{\mathrm{Ce}}: V_{\ddot{\mathrm{O}}}$ aggregates within the $\mathrm{H}$. As a consequence, the linear decrease in $\ln B_{0}$ vs. $\ln \left(2 V_{a t}\right)$ implies a corresponding linear trend in $\ln B_{0}$ vs. $\ln x$. Therefore, the absence of any discontinuity or slope change at $0.3 \leq x \leq 0.4$ means that $B_{0}$ is insensitive to the structural change occurring at the $\mathrm{F} / \mathrm{H}$ boundary. For the sake of comparison, data deriving from Lu-doped ceria taken from [12] are reported in the inset to Figure 6. $B_{0}$ values of Lu-doped ceria were obtained by fitting experimental data to the third order Vinet EoS, in analogy with the data treatment performed on Sm-doped ceria. As mentioned above, the Lu-doped ceria system presents different structural regions depending on the Lu content: the $\mathrm{F}$ phase up to $x \sim 0.4$; the $(F+C)$ two-phase field for $x$ ranging between $\sim 0.4$ and $\sim 0.8$; and a C-based solid solution containing F-structured $\mathrm{CeO}_{2}$ domains at higher $x$. The occurrence of the two-phase field is due to the large size difference between $\mathrm{Ce}^{4+}(\mathrm{CN}: 8)$ and $\mathrm{Lu}^{3+}(\mathrm{CN}: 6)$, which hinders the formation of the $\mathrm{H}$ phase. 
The regular decrease of $\ln B_{0}$ vs. $\ln \left(2 V_{a t}\right)$, observed in the inset to Figure 6 , resembles the behavior of $\mathrm{Sm}$-doped ceria, and suggests that even in this system $B_{0}$ is insensitive to structural changes.

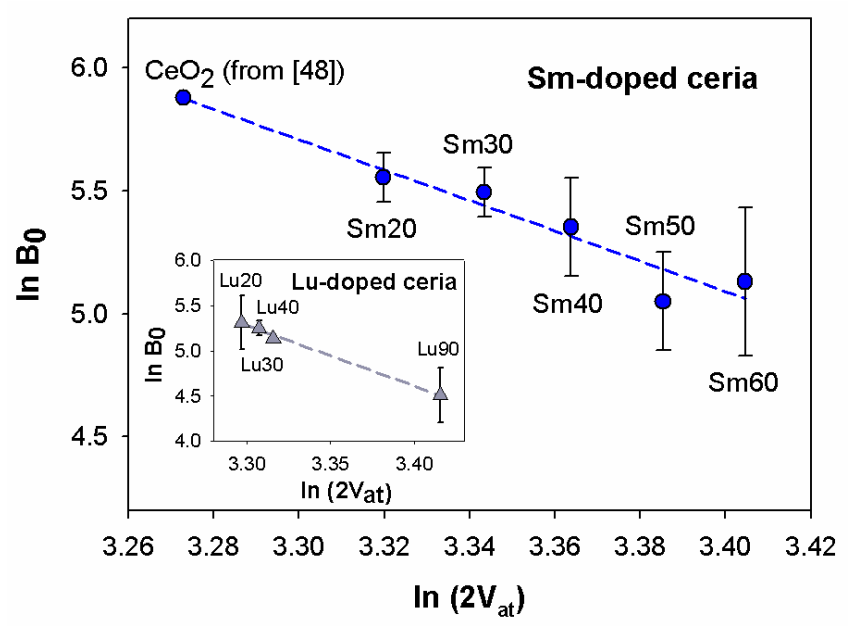

Figure 7. Trend of $\ln B_{0}$ as a function of $\ln \left(2 V_{a t}\right) . B_{0}$ and $2 V_{a t}$ values of Sm-doped ceria are obtained from EoS fits and Rietveld refinements, respectively. Data of $\mathrm{CeO}_{2}$ are taken from [48]. Cell volumes of samples Sm 20 and Sm30 are multiplied by 8 in order to make them comparable with those of Sm40, Sm50 ad Sm60. Inset: trend of $\ln B_{0}$ vs. $\ln \left(2 V_{a t}\right)$ for Lu-doped ceria: data are taken from [13]. In both diagrams the dashed line is the regression line interpolating data. Horizontal error bars are hidden by data markers.

$\ln B_{0}$ vs. $\ln \left(2 V_{a t}\right)$ data of both systems can be interpolated by a regression line that satisfactorily fits experimental points $\left(r^{2}=0.94\right.$ and $r^{2}=0.99 \mathrm{for} \mathrm{Sm}$ - and Lu-doped ceria, respectively), as highlighted in Figure 7. The striking result here is the closeness of the two slopes: $m=6.1$ and $m=6.6$ for the $\mathrm{Sm}$ - and Lu-doped ceria, respectively. The decreasing trend is thus much steeper than expected for an oxide, according to [51]. This evidence can be most probably be interpreted as a direct consequence of the $\mathrm{Ce}^{4+}$ replacement by $\mathrm{Sm}^{3+}$ or $\mathrm{Lu}^{3+}$, the effects of which are two-fold: on the one hand, they cause an enlargement of the cell due to the incorporation of a larger ion $\left(\mathrm{Sm}^{3+}, \mathrm{CN}: 8, r=1.079 \AA\right.$; $\mathrm{Lu}^{3+}, \mathrm{CN}: 8, r=0.977 \AA$ [25]) in place of a smaller one $\left(\mathrm{Ce}^{4+}, \mathrm{CN}: 8, r=0.97 \AA\right.$ [25]); on the other hand, the introduction of oxygen vacancies is generally considered responsible for lattice shrinkage [53-55]. In this respect, Raman spectroscopy offers a precious contribution to comprehension of the vacancies effect, since it is possible to apply a correction to the observed Raman shift of the $\mathrm{CeO}_{2} \mathrm{~F}_{2 g}$ symmetric vibration mode and separate the size from the vacancies effect [53]. Once subtracted from the size effect, the trend of the corrected Raman shifts increases along with increases of the amount of trivalent ions, which can be explained as a consequence of the lattice shrinkage brought about by the introduction of oxygen vacancies. The described result was obtained both for Sm- [24,41] and Gd-doped ceria [24] and can be conceivably predicted for all the RE-doped ceria systems within the $F$ and $H$ phases. From the previous discussion it can thus be expected that mean atomic volume is affected by the two competitive effects, namely, the dopant size and vacancies introduction. Therefore, the mean atomic volume increases with increases in $\mathrm{Sm}^{3+}$ or $\mathrm{Lu}^{3+}$ amounts, but less so than if vacancies were not created. Under these circumstances, a steeper decrease of $\ln B_{0}$ vs. $\ln \left(2 V_{a t}\right)$ is expected, and indeed was observed in our samples belonging to both systems with respect to the ones reported in [51].

A further remarkable issue concerning the effect of pressure on cell volume can be inferred from the data reported in Figure 5. Even at a first glance, Sm20 can be distinguished from other compositions due to roughly linear decreases in its cell volume vs. applied pressure, which indicate that the bulk modulus did not present any substantial change as a result of pressure within the considered range. All other samples, on the contrary, showed a progressively less steep decrease with increasing pressure, thus indicating an increase in the bulk modulus and a decrease in compressibility. Moreover, softening 
of the volume decrease vs. pressure decrease became more and more marked with increasing amounts of Sm. This substantial difference between samples with $x<\sim 0.3$ and $x \geq \sim 0.3$ seems to go hand in hand with the structural modifications occurring at $x \sim 0.3$, namely, the transition from $\mathrm{F}$ to $\mathrm{H}$. Within this scenario, it can thus be deduced that the $\mathrm{F}$ phase is more tolerant toward compression with respect to $\mathrm{C}$, or in other words that $\mathrm{C}$-based microdomains tend to stiffen structures and make them less compressible. This conclusion is also corroborated by the general consideration that the fluorite structure of $\mathrm{CeO}_{2}$ is indeed very prone to the replacement of $\mathrm{Ce}^{4+}$ by larger atoms up to a remarkable substitution degree [3]. An F-based solid solution preserving the atomic arrangement of $\mathrm{CeO}_{2}$ is in fact stable in $\mathrm{Ce}_{1-x} \mathrm{RE}_{x} \mathrm{O}_{2-x / 2}$ systems (e.g., up to $x \sim 0.2$ or 0.25 for $\mathrm{Gd}^{3+}[28,56] ; x \sim 0.25$ for $\mathrm{Y}^{3+}[26] ; x \sim$ 0.3 for $\mathrm{Sm}^{3+}$ [28] and $\mathrm{Er}^{3+}$ [57]; $x \sim 0.4$ for $\mathrm{Tm}^{3+}$ [54], $\mathrm{Lu}^{3+}$ [28] and $\mathrm{Nd}^{3+}$ [57]; $x \sim 0.5$ for $\mathrm{Yb}^{3+}$ [54] and an $\mathrm{Nd}^{3+} / \mathrm{Dy}^{3+}$ mixture [58]; and $x \sim 0.6$ for $\mathrm{La}^{3+}$ [57]). On the contrary, a much narrower stability region occurs for $\mathrm{RE}_{2} \mathrm{O}_{3}$-based C-structured solid solutions where $\mathrm{RE}^{3+}$ is partially substituted by $\mathrm{Ce}^{4+}$. For $\mathrm{RE} \equiv \mathrm{Lu}$, for example, a maximum $10 \%$ substitution by $\mathrm{Ce}^{4+}$ is in fact possible, while for $\mathrm{RE}$ $\equiv \mathrm{Gd}$ and $\mathrm{Sm}$, the maximum substitution degree of trivalent ions reaches $20 \%$ [28].

The stiffening effect of the $C$ phase is further confirmed by the behavior shown in Figure 8 related to the cell volume vs. applied pressure up to 7 GPa observed in Lu-doped ceria, which is based on the experimental results reported in [12]. It can be noticed that samples Lu20, Lu30 and Lu40, crystallizing in the F structure, are characterized by a roughly linear decrease within the pressure range considered; conversely, Lu90, crystallizing in the C structure, presents a softening of the volume decrease already revealed for C-containing compositions belonging to Sm-doped ceria, thus confirming the higher resistance to compression of this structure.

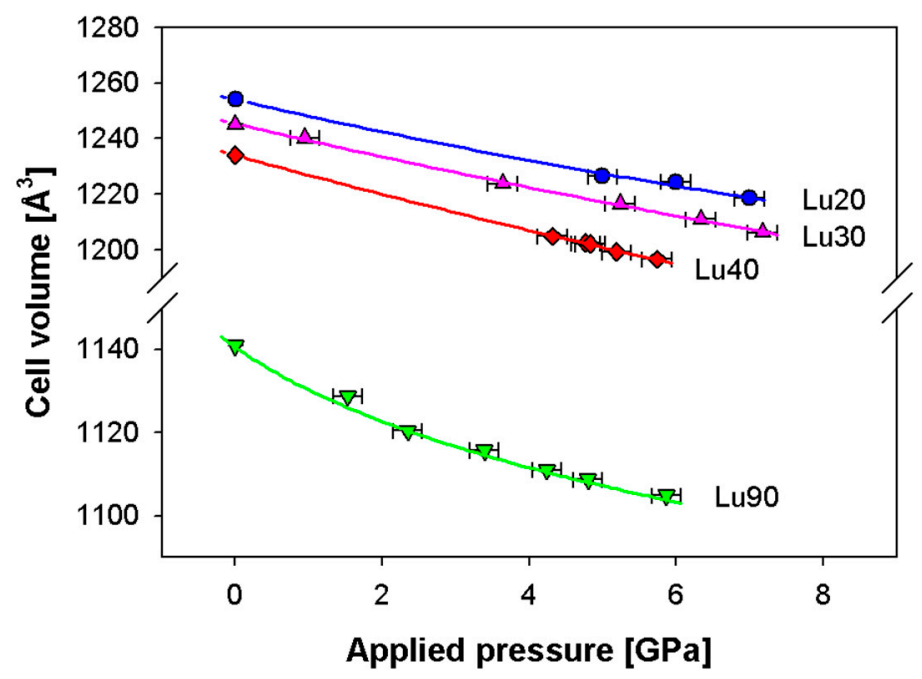

Figure 8. Dependence of the Lu-doped ceria cell volume vs. applied pressure; experimental data are taken from [13] and fitted by the third order Vinet EoS (continuous lines). Cell volumes of samples Lu20, Lu30 and Lu40 are multiplied by 8 in order to make them comparable with Sm90. Vertical error bars are hidden by data markers.

\section{Conclusions}

An in situ high-pressure structural investigation was performed by powder $X$-ray diffraction at the Elettra synchrotron facility on samples belonging to the $\mathrm{Ce}_{1-x} \mathrm{Sm}_{x} \mathrm{O}_{2-x / 2}$ system with nominal $x=0.2$, $0.3,0.4,0.5$ and 0.6 . Rietveld refinements performed on the collected diffraction patterns provided optimized values of the cell volumes at the different pressures, which were then interpolated through the third order Vinet EoS. The fit allowed refined values of the bulk modulus to be obtained at zero pressure $\left(B_{0}\right)$. Results were discussed in comparison to the ones previously obtained from Lu-doped ceria. Two main conclusions can be drawn from this study. 
- $\quad$ The $\ln B_{0}$ vs. $\ln \left(2 V_{a t}\right)$ trend provided a linear decrease as expected, but the slope of the regression line was around -6 for both systems, instead of ranging between -3 and -4 , which is at odds with predictions for oxides. This evidence can be interpreted considering that a linear correlation exists between the $\mathrm{RE}^{3+}$ content and the oxygen vacancies amount; the rise in the vacancies content occurring with increasing the $\mathrm{RE}^{3+}$ amount causes a lattice shrinkage and limits the increase of the mean atomic volume.

- While samples crystallizing in the F structure showed a roughly linear decrease of the cell volume vs. pressure, the ones containing C-based microdomains demonstrated a softening of cell volume decrease with increasing pressure. This evidence, emerging both from $\mathrm{Sm}$ - and Lu-doped ceria, suggests that the presence of $C$ stiffens a structure, making it less and less compressible with increasing pressure.

Supplementary Materials: The following are available online at http:/www.mdpi.com/1996-1073/13/7/1558/s1, Table S1: Hybrid (H) structural model compared to the $\mathrm{F}$ structure typical of $\mathrm{CeO}_{2}$ and to the $\mathrm{C}$ structure typical of sesquioxides of heavy rare earths.

Author Contributions: Conceptualization, C.A., M.M.C. and M.P.; methodology, C.A.; formal analysis, C.A.; investigation, M.P. and B.J.; resources, M.P. and C.A.; data curation, S.M.; writing-original draft preparation, C.A.; writing-review and editing, C.A., S.M., M.M.C., B.J. and M.P.; visualization, S.M. All authors have read and agreed to the published version of the manuscript.

Funding: This research received no external funding.

Acknowledgments: The Elettra Synchrotron Radiation Facility is acknowledged for the provision of beam time. B.J. acknowledges IISc Bangalore and ICTP Trieste for the award of IISc-ICTP fellowship.

Conflicts of Interest: The authors declare no conflict of interest.

\section{References}

1. Omar, S.; Wachsman, E.D.; Jones, J.L.; Nino, J.C. Crystal structure-ionic conductivity relationships in doped ceria. J. Am. Ceram. Soc. 2009, 92, 2674-2681. [CrossRef]

2. Artini, C.; Pani, M.; Lausi, A.; Masini, R.; Costa, G.A. High temperature structural study of Gd-doped ceria by synchrotron X-ray diffraction (673 K $\leq \mathrm{T} \leq 1073 \mathrm{~K}$ ). Inorg. Chem. 2014, 53, 10140-10149. [CrossRef] [PubMed]

3. Presto, S.; Artini, C.; Pani, M.; Carnasciali, M.M.; Massardo, S.; Viviani, M. Ionic conductivity and local structural features in $\mathrm{Ce}_{1-x} \mathrm{Sm}_{\mathrm{x}} \mathrm{O}_{2-\mathrm{x} / 2}$. Phys. Chem. Chem. Phys. 2018, 20, 28338-28345. [CrossRef]

4. Steele, B.C.H. Appraisal of $\mathrm{Ce}_{1-\mathrm{x}} \mathrm{Gd}_{\mathrm{y}} \mathrm{O}_{2-\mathrm{y} / 2}$ electrolytes for IT-SOFC operation at $500^{\circ} \mathrm{C}$. Solid State Ion. 2000, 129, 95-110. [CrossRef]

5. Artini, C. RE-doped ceria systems and their performance as solid electrolytes: A puzzling tangle of structural issues at the average and local scale. Inorg. Chem. 2018, 57, 13047-13062. [CrossRef]

6. Coduri, M.; Checchia, S.; Longhi, M.; Ceresoli, D.; Scavini, M. Rare earth doped ceria: The complex connection between structure and properties. Front. Chem. 2018, 6, 526. [CrossRef]

7. Artini, C.; Presto, S.; Massardo, S.; Pani, M.; Carnasciali, M.M.; Viviani, M. Transport properties and high temperature Raman features of heavily Gd-doped ceria. Energies 2019, 12, 4148. [CrossRef]

8. Rupp, J.L.M.; Infortuna, A.; Gauckler, L.J. Thermodynamic stability of gadolinia-doped ceria thin film electrolytes for micro-solid oxide fuel cells. J. Am. Ceram. Soc. 2007, 90, 1792-1797. [CrossRef]

9. Taniguchi, I.; Van Landschoot, R.C.; Schoonman, J. Electrostatic spray deposition of $\mathrm{Gd}_{0.1} \mathrm{Ce}_{0.9} \mathrm{O}_{1.95}$ and $\mathrm{La}_{0.9} \mathrm{Sr}_{0.1} \mathrm{Ga}_{0.8} \mathrm{Mg}_{0.2} \mathrm{O}_{2.87}$ thin films. Solid State Ion. 2003, 160, 271-279. [CrossRef]

10. Burbano, M.; Marrocchelli, D.; Watson, G.W. Strain effects on the ionic conductivity of Y-doped ceria: A simulation study. J. Electroceram. 2014, 32, 28-36. [CrossRef]

11. Kant, K.M.; Esposito, V.; Pryds, N. Strain induced ionic conductivity enhancement in epitaxial $\mathrm{Ce}_{0.9} \mathrm{Gd}_{0.1} \mathrm{O}_{2-\delta}$ thin films. Appl. Phys. Lett. 2012, 100, 033105. [CrossRef]

12. Rainwater, B.H.; Velisavljevic, N.; Park, C.; Sun, H.; Waller, G.H.; Tsoi, G.M.; Vohra, Y.K.; Liu, M. High pressure structural study of samarium doped $\mathrm{CeO}_{2}$ oxygen vacancy conductor-Insight into the dopant concentration relationship to the strain effect in thin film ionic conductors. Solid State Ion. 2016, 292, 59-65. [CrossRef] 
13. Artini, C.; Joseph, B.; Costa, G.A.; Pani, M. Crystallographic properties of Lu-doped ceria, $\mathrm{Ce}_{1-\mathrm{x}} \mathrm{Lu}_{\mathrm{x}} \mathrm{O}_{2-\mathrm{x} / 2 \text {, }}$ at pressures up to $7 \mathrm{GPa}$. Solid State Ion. 2018, 320, 152-158. [CrossRef]

14. Lee, K.-R.; Ahn, K.; Chung, Y.-C.; Lee, J.-H.; Yoo, H.-I. Lattice distortion effect on electrical properties of GDC thin films: Experimental evidence and computational simulation. Solid State Ion. 2012, 229, 45-53. [CrossRef]

15. Spiridigliozzi, L.; Ferone, C.; Cioffi, R.; Accardo, G.; Frattini, D.; Dell'Agli, G. Entropy-stabilized oxides owning fluorite structure obtained by hydrothermal treatment. Materials 2020, 13, 558. [CrossRef]

16. Sarkar, A.; Loho, C.; Velasco, L.; Thomas, T.; Battacharya, S.S.; Hahn, H.; Djenadic, R. Multicomponent equiatomic rare earth oxides with a narrow band gap and associated praseodymium multivalenc. Dalton Trans. 2017, 46, 12167-12176. [CrossRef] [PubMed]

17. Coduri, M.; Masala, P.; Allieta, M.; Peral, I.; Brunelli, M.; Biffi, C.A.; Scavini, M. Phase transformations in the $\mathrm{CeO}_{2}-\mathrm{Sm}_{2} \mathrm{O}_{3}$ system: A multiscale powder diffraction investigation. Inorg. Chem. 2018, 57, 879-891. [CrossRef]

18. Artini, C.; Nelli, I.; Pani, M.; Costa, G.A.; Caratto, V.; Locardi, F. Thermal decomposition of Ce-Sm and Ce-Lu mixed oxalates: Influence of the Sm- and Lu-doped ceria structure. Thermochim. Acta 2017, 651, 100-107. [CrossRef]

19. Omar, S.; Wachsman, E.; Nino, J. Higher conductivity $\mathrm{Sm}^{3+}$ and $\mathrm{Nd}^{3+}$ co-doped ceria-based electrolyte materials. Solid State Ion. 2008, 178, 1890-1897. [CrossRef]

20. Acharya, S.A.; Gaikwad, V.M.; D'Souza, S.W.; Barman, S.R. Gd/Sm dopant-modified oxidation state and defect generation in nano-ceria. Solid State Ion. 2014, 260, 21-29. [CrossRef]

21. Nitani, H.; Nakagawa, T.; Yamanouchi, M.; Osuki, T.; Yuya, M.; Yamamoto, T.A. XAFS and XRD study of ceria doped with Pr, Nd and Sm. Mater. Lett. 2004, 58, 2076-2081. [CrossRef]

22. Artini, C.; Costa, G.A.; Pani, M.; Lausi, A.; Plaisier, J. Structural characterization of the $\mathrm{CeO}_{2} / \mathrm{Gd}_{2} \mathrm{O}_{3}$ mixed system by synchrotron X-ray diffraction. J. Solid State Chem. 2012, 190, 24-28. [CrossRef]

23. Tianshu, Z.; Hing, P.; Huang, H.; Kilner, J. Ionic conductivity in the $\mathrm{CeO}_{2}-\mathrm{Gd}_{2} \mathrm{O}_{3}$ system $(0.05 \leq \mathrm{Gd} / \mathrm{Ce} \leq 0.4)$ prepared by oxalate coprecipitation. Solid State Ion. 2002, 148, 567-573. [CrossRef]

24. Artini, C.; Pani, M.; Carnasciali, M.M.; Buscaglia, M.T.; Plaisier, J.; Costa, G.A. Structural features of Sm- and Gd-doped ceria studied by synchrotron X-ray diffraction and $\mu$-Raman spectroscopy. Inorg. Chem. 2015, 54, 4126-4137. [CrossRef]

25. Shannon, R.D. Revised effective ionic radii and systematic studies of interatomic distances in halides and chalcogenides. Acta Cryst. A 1976, 32, 751-767. [CrossRef]

26. Coduri, M.; Scavini, M.; Allieta, M.; Brunelli, M.; Ferrero, C. Defect structure of Y-doped ceria on different length scales. Chem. Mater. 2013, 25, 4278-4289. [CrossRef]

27. Coduri, M.; Scavini, M.; Pani, M.; Carnasciali, M.M.; Klein, H.; Artini, C. From nano to microcrystals: Effect of different synthetic pathways on defects architecture in heavily Gd-doped ceria. Phys. Chem. Chem. Phys. 2017, 19, 11612-11630. [CrossRef]

28. Artini, C.; Pani, M.; Carnasciali, M.M.; Plaisier, J.R.; Costa, G.A. Lu-, Sm- and Gd-doped ceria: A comparative approach to their structural properties. Inorg. Chem. 2016, 55, 10567-10579. [CrossRef]

29. Lotti, P.; Milani, S.; Merlini, M.; Joseph, B.; Alabarse, F.; Lausi, A. Single-crystal diffraction at the high-pressure Indo-Italian beamline Xpress at Elettra, Trieste. J. Synchrot. Radiat. 2020, 27, 222-229. [CrossRef]

30. Vinet, P.; Smith, J.R.; Ferrante, J.; Rose, J.H. Temperature effects on the universal equation of state of solids. Phys. Rev. B 1987, 35, 1945-1953. [CrossRef]

31. Artini, C.; Costa, G.A.; Carnasciali, M.M.; Masini, R. Stability fields and structural properties of intra rare earths perovskites. J. Alloy Compd. 2010, 494, 336-339. [CrossRef]

32. Artini, C.; Costa, G.A.; Masini, R. Study of the formation temperature of mixed $\mathrm{LaREO}_{3}(\mathrm{RE} \equiv \mathrm{Dy}, \mathrm{Ho}, \mathrm{Er}, \mathrm{Tm}$, $\mathrm{Yb}, \mathrm{Lu}$ ) and $\mathrm{NdGdO}_{3}$ oxides. J. Therm. Anal. Calorim. 2011, 103, 17-21. [CrossRef]

33. Rodriguez-Carvajal, J. Recent advances in magnetic structure determination by neutron powder diffraction. Phys. B Condens. Matter 1993, 192, 55-69. [CrossRef]

34. Gonzalez-Platas, J.; Alvaro, M.; Nestola, F.; Angel, R. EosFit7-GUI: A new graphical user interface for equation of state calculations, analyses and teaching. J. Appl. Cryst. 2016, 49, 1377-1382. [CrossRef]

35. Eyring, L. The binary rare earth oxides. In Handbook on the Physics and Chemistry of Rare Earths; Gschneidner, K.A., Jr., Eyring, L., Eds.; North Holland: Amsterdam, The Netherlands, 1979; Volume 3, pp. 337-399.

36. Vanpoucke, D.E.P.; Bultinck, P.; Cottenier, S.; Van Speybroeck, V.; Van Driessche, I. Density functional theory study of $\mathrm{La}_{2} \mathrm{Ce}_{2} \mathrm{O}_{7}$ : Disordered fluorite versus pyrochlore structure. Phys. Rev. B 2011, 84, 054110. [CrossRef] 
37. Minervini, L.; Grimes, R.W. Disorder in pyrochlore oxides. J. Am. Ceram. Soc. 2000, 83, 1873-1878. [CrossRef]

38. Chen, W.; Navrotsky, A. Thermochemical study of trivalent-doped ceria systems: $\mathrm{CeO}_{2}-\mathrm{MO}_{1.5}(\mathrm{M}=\mathrm{La}, \mathrm{Gd}$, and Y). J. Mater. Res. 2006, 21, 3242-3251. [CrossRef]

39. Minervini, L.; Zacate, M.O.; Grimes, R.W. Defect cluster formation in $\mathrm{M}_{2} \mathrm{O}_{3}$-doped $\mathrm{CeO}_{2}$. Solid State Ion. 1999, 116, 339-349. [CrossRef]

40. Wang, B.; Lewis, R.J. Cormack, A.N. Computer simulations of large-scale defect clustering and nanodomain structure in gadolinia-doped ceria. Acta Mater. 2011, 59, 2035-2045. [CrossRef]

41. Artini, C.; Carnasciali, M.M.; Viviani, M.; Presto, S.; Plaisier, J.R.; Costa, G.A.; Pani, M. Structural properties of Sm-doped ceria electrolytes at the fuel cell operating temperatures. Solid State Ion. 2018, 315, 85-91. [CrossRef]

42. Ubaldini, A.; Carnasciali, M.M. Raman Characterisation of powder of cubic $\mathrm{RE}_{2} \mathrm{O}_{3}(\mathrm{RE}=\mathrm{Nd}, \mathrm{Gd}, \mathrm{Dy}, \mathrm{Tm}$, and $\mathrm{Lu}$ ), $\mathrm{Sc}_{2} \mathrm{O}_{3}$ and $\mathrm{Y}_{2} \mathrm{O}_{3}$. J. Alloy Compd. 2008, 454, 374-378. [CrossRef]

43. Artini, C.; Carnasciali, M.M.; Costa, G.A.; Plaisier, J.R.; Pani, M. A novel method for the evaluation of the Rare Earth (RE) coordination number in RE-doped ceria through Raman spectroscopy. Solid State Ion. 2017, 311, 90-97. [CrossRef]

44. Murnaghan, F.D. The compressibility of media under extreme pressures. Proc. Natl. Acad. Sci. USA 1944, 30, 244-247. [CrossRef] [PubMed]

45. Birch, F. Finite elastic strain of cubic crystals. Phys. Rev. B 1947, 71, 809-824. [CrossRef]

46. Poirier, J.P.; Tarantola, A. A logarithmic equation of state. Phys. Earth Planet Int. 1998, 109, 1-8. [CrossRef]

47. Pavese, A. Pressure-volume-temperature equations of state: A comparative study based on numerical simulations. Phys. Chem. Miner. 2002, 29, 43-51. [CrossRef]

48. Hill, S.E.; Catlow, C.R.A. A Hartree-Fock periodic study of bulk ceria. J. Phys. Chem. Solids 1993, 54, 411-419. [CrossRef]

49. Gerward, L.; Staun Olsen, J. Powder diffraction analysis of cerium oxide at high pressure. Powder Diffr. 1993, 8, 127-130. [CrossRef]

50. Gerward, L.; Staun Olsen, J.; Petit, L.; Vaitheeswaran, G.; Kanchana, V.; Svane, A. Bulk modulus of $\mathrm{CeO}_{2}$ and $\mathrm{PrO}_{2}$ - An experimental and theoretical study. J. Alloy Compd. 2005, 400, 56-61. [CrossRef]

51. Anderson, O.L.; Nafe, J.E. The bulk modulus-volume relationship for oxides compounds and related geophysical problems. J. Geophys. Res. 1965, 70, 3951-3963. [CrossRef]

52. Zen, E. Validity of "Vegard's law". Am. Mineral. 1956, 41, 523-524.

53. McBride, J.R.; Hass, K.C.; Pointdexter, B.D.; Weber, W.H. Raman and X-ray studies of $\mathrm{Ce}_{1-x} \mathrm{RE}_{x} \mathrm{O}_{2-y}$, where RE=La, Pr, Nd, Eu, Gd, and Tb. J. Appl. Phys. 1994, 76, 2435-2441. [CrossRef]

54. Mandal, B.P.; Grover, V.; Roy, M.; Tyagi, A.K. X-ray diffraction and Raman spectroscopic investigation on the phase relations in $\mathrm{Yb}_{2} \mathrm{O}_{3}$ - and $\mathrm{Tm}_{2} \mathrm{O}_{3}$-substituted $\mathrm{CeO}_{2}$. J. Am. Ceram. Soc. 2007, 90, 2961-2965. [CrossRef]

55. Kossoy, A.; Wang, Q.; Korobko, R.; Grover, V.; Feldman, Y.; Wachtel, E.; Tyagi, A.K.; Frenkel, A.I.; Lubomirsky, I. Evolution of the local structure at the phase transition in $\mathrm{CeO}_{2}-\mathrm{Gd}_{2} \mathrm{O}_{3}$ solid solutions. Phys. Rev. B 2013, 87, 054101. [CrossRef]

56. Scavini, M.; Coduri, M.; Allieta, M.; Brunelli, M.; Ferrero, C. Probing complex disorder in $\mathrm{Ce}_{1-\mathrm{x}} \mathrm{Gd}_{\mathrm{x}} \mathrm{O}_{2-\mathrm{x} / 2}$ using the pair distribution function analysis. Chem. Mater. 2012, 24, 1338-1345. [CrossRef]

57. Horlait, D.; Claparède, L.; Clavier, N.; Szencnekt, S.; Dacheux, N.; Ravaux, J.; Podor, R. Stability and structural evolution of $\mathrm{Ce}^{\mathrm{IV}}{ }_{1-x} \mathrm{Ln}^{\mathrm{III}}{ }_{x} \mathrm{O}_{2-x / 2}$ solid solutions: A coupled $\mu$-Raman/XRD approach. Inorg. Chem. 2011, 50, 150-161. [CrossRef]

58. Artini, C.; Gigli, L.; Carnasciali, M.M.; Pani, M. Structural properties of the (Nd,Dy)-doped ceria system by synchrotron X-ray diffraction. Inorganics 2019, 7, 94. [CrossRef]

(C) 2020 by the authors. Licensee MDPI, Basel, Switzerland. This article is an open access article distributed under the terms and conditions of the Creative Commons Attribution (CC BY) license (http://creativecommons.org/licenses/by/4.0/). 